\title{
The Application Research of BIM Technology in Architectural Design
}

\author{
Qiang He \\ School of Civil Engineering, Xuzhou University of Technology, China
}

Keywords: BIM technology, residential construction, architectural design, application

\begin{abstract}
Residential building is the main part of construction and advanced residential building design technology will be important to solve the problem of energy crisis, environmental degradation etc. Therefore the research new residential building design technology has a strong theoretical and practical significance. In architectural design, based on the application of BIM technology system created by the virtual building model, contains all of the required to build a building component. Since ancient times, architectural design method with alternating update time, all kinds of design methods to promote the further development of the building, including housing for people to use most of the architectural form, develop more advanced technology and method to design the residential, management, residential, let the improvement of the living environment of people further, become the main content of the analysis and research.
\end{abstract}

\section{Introduction}

With the development of social civilization, information technology has been for manufacturing, electronics and other industries, has brought the revolutionary change and construction informatization level still has been in a low level. In the pursuit of low energy consumption, low pollution, against the background of sustainable development, the engineering construction of informatization has become the era development of inevitable direction. BIM technology as a new generation of innovative way of computer aided design tools and production. Become the construction of information technology in the construction industry application directly.

\section{The definition and characteristic of BIM technology}

BIM is Building Information Modeling. BIM is a kind of new building model design techniques, using 3D digital technology, digital technology and computer technology, database establishment conforms to the actual project [1]. Include not only building geometric information and status information and professional attributes, including non building of movement and spatial behavior, etc.

BIM based on 3D digital technology, the integration of all kinds of information related to construction engineering project engineering data model, is the project facilities entities and functional characteristics of digital expression (Fig. 1). Entity model not only has 3D geometry information, also contains a large number of the geometry information, such as construction material, weight, price and schedule, etc., and thus can be used to simulate the behavior of the real world. BIM application throughout the whole life cycle of projects at various stages includes planning, design, and construction and operation management.

Designers use BIM technology, can greatly reduce the workload. Because of the use of BIM technology design of building model, already contains information such as building structure, material, directly in energy consumption analysis software to carry on the analysis, can be concluded that the energy consumption situation, do not need to spend a lot of time for data input, thus simplify the workload and work process [1]. 


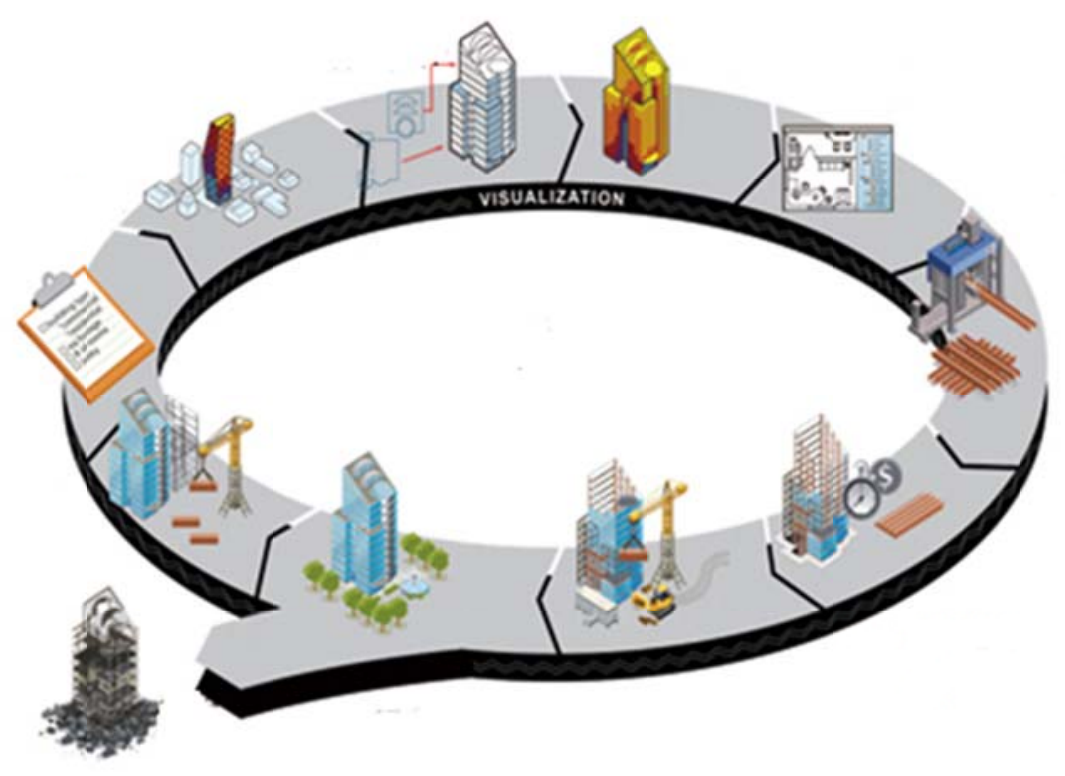

Fig. 1 Project life cycle information based on BIM implementation

\section{The main technical content of BIM technology}

Virtual simulation construction mainly includes the following contents:

Three-dimensional modeling technology. Using the full dimensional modeling and building information model (BIM) technology, set up for the virtual construction and construction process control, cost control of construction model. The model parameters can be linked with influence of soil properties, to reflect the construction model and design model of interaction between, construction model to have reusability, therefore it is necessary to establish the construction of product master model description framework, along with the advancement of product development and the construction process, increasingly detailed model description [2]. Through the BIM technology, maintain the consistency of models and model information can be inherited, realize the virtual construction process on the surface of the preparation stage and the effective integration.

Simulation technology. Computer simulations is the application of computer to the complex reality system forms through abstract and simplify the system model, and then based on the analysis of running this model, and a series of statistical performance is obtained [2]. Basic steps of the simulation are as follows: research, collect data, establish a system model, to determine the simulation algorithm, simulation model is set up, run simulation model, the output, including numerical simulation, visual simulation and virtual reality VR simulation.

Optimization techniques. Optimization technology will be the reality of the physical model of the process into a mathematical model, by setting the optimization goal and operation method, under the condition of the set of constraints, the objective function to achieve the optimal, so as to provide scientific and quantitative basis for decision makers [2]. It uses the method includes: linear programming, nonlinear programming, dynamic programming, operations research, decision theory and game theory, and so on.

Virtual reality technology. The operator immersion and interact with it, through a variety of media to sensory stimulation, to solve the problem of virtual construction is required in a virtual environment, virtual reality technology is the core technology of virtual construction system. Virtual reality technology is a blend of the artificial intelligence, computer graphics, human-machine interface, multimedia industrial building technology, network technology, electronic technology, mechanical technology and other high and new technology of comprehensive information technology. Purpose is to use the computer hardware, software, and various sensors to create a fusion of visual, hearing, touch, and even the sense of smell, immersive virtual environment [3]. Operators of 
immersion and interact with it, through a variety of media to sensory stimulation, get clear and intuitive understanding of required to solve the problem.

\section{The application of BIM technology in the construction design}

BIM technology is throughout the whole process of construction of life mode. Construction stage of project construction is a key link in the process of construction project planning and design into reality, as the carrier of the construction enterprise shall establish a BIM application project management information system, to enhance the level of construction and ensure the construction quality, get more economic benefits? BIM technology in the construction stage specific application value is embodied in the following aspects:

4D rendering. According to the construction plan, image display area and large equipment arrangement, complex node construction scheme, construction sequence, the choice of 4D simulation, were compared for different construction scheme selection, etc. Built BIM model can be used as a secondary rendering the model base for the development [4]. Greatly improve the accuracy and efficiency of the 3D rendering, more intuitive to the owner of the publicity, increase the winning probability.

Quickly calculate the amount. BIM database creation is through the establishment of 5D relational database. Can accurately fast calculation of quantities; enhance the accuracy and efficiency of construction budget. Because BIM database data granularity level component can quickly provide support data needed for the project lines management information, enhance the efficiency of construction management [3]. Statistical Material is extracted through the BIM model materials, equipment, control cost and forecast cost, for the construction project bidding and construction process of cost control to provide a reasonable basis.

Accurate plan, reduce waste. It is difficult to realize the root cause of the construction enterprise of fine management lies in the vast amounts of engineering data cannot be accurately obtain to support resource planning, the empiricism [4]. And the emergence of BIM can make relevant management personnel data quickly and accurately obtain engineering foundation, accurate talent plan for construction enterprises to provide effective support, greatly reducing the waste of resources, logistics and warehousing link, in order to realize acquisition, the limit cost control to provide technical support.

Virtual construction, effective collaboration. 3D visualization functions plus time dimension can make the virtual construction. Anytime and anywhere is quickly and directly to the construction plan and the actual progress, at the same time for effective coordination. And quality supervision party, and even a non-engineering industry was born of the owners, knew all about the various problems and situation of the project [5]. So with BIM technology combined with the construction scheme, construction simulation and field video monitoring, greatly reduce the construction quality, safety problems, reduce rework and rectification.

Collision check, Reduce rework. BIM is the most intuitive features a 3D visualization, using the 3D BIM technology can collision check in early. Optimization of engineering design, reduce the possible errors in the construction phase the possibility of loss and rework [4]. Construction personnel can make use of the optimized 3D pipeline. Construction clarifications, construction simulation, improve the quality of construction, but also improve the ability of communication with the owner.

\section{The application of BIM technology in architectural design}

Residential external modeling has certain requirements, should not only consider the appearance of beauty, economic conditions and practical problems such as climate, but also by improving the construction of practical value, let residents' satisfaction. Also should give full consideration to the natural factors such as landform and physiognomy, and the local customs and weather conditions. The traffic flow can make sub channel, and can guarantee the safety of the residents.

Using 3D for simplifying 2D complex components. BIM technology using the visualization of $3 \mathrm{D}$ design to replace complex two-dimensional artifacts, when making the design of the building, for 
all kinds of prefabricated components, such as precast stairs, precast beams and prefabricated wall, etc. [5]. That is a standardized insert model, at the design stage only need to use 3D model to $2 \mathrm{~d}$ graphics to export, and then to make simple drawings processing, not only can now set, peaceful section design of components, can also improve the information related to the reserved and presupposition, avoid any errors, improve the quality of design drawings, such as Fig. 2.

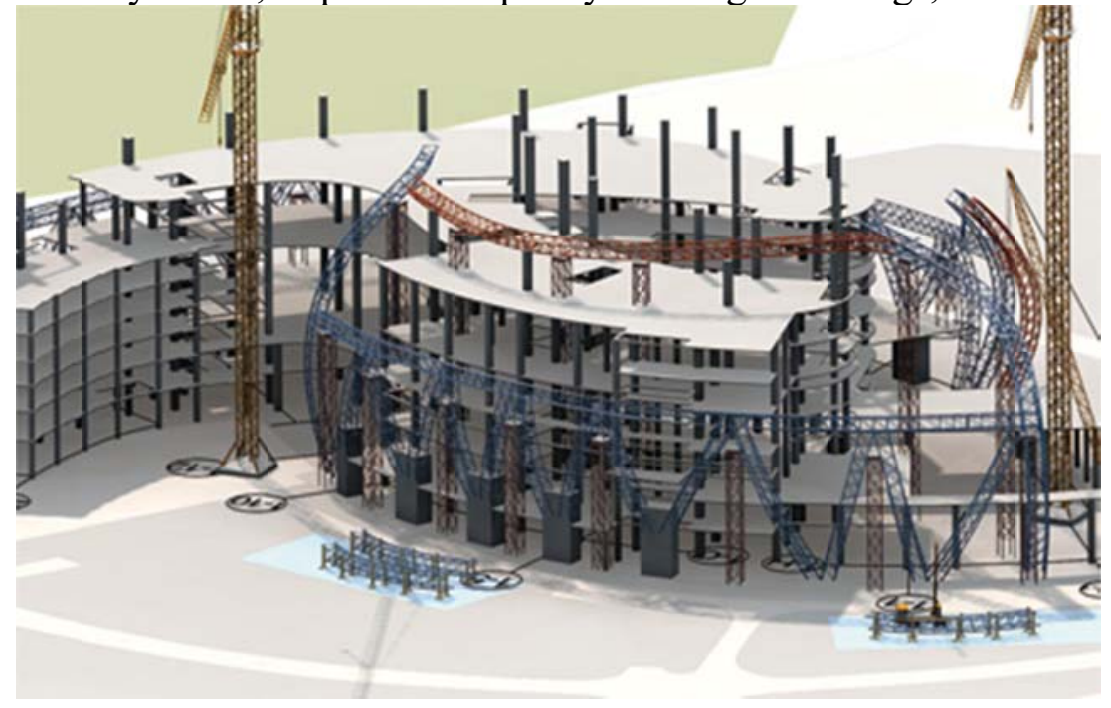

Fig. 2 3D design model

BIM for residential space planning. Analyze the terrain is one of the important conditions of design, the application of BIM can accelerate the speed of spatial analysis, which includes visibility analysis and indoor vision analysis of two aspects [5]. When the height can't be too big adjustment, the engineer don't want to because of the large span structure, affect the original design requirement for the use of space.

Providing visual decoration model. Using BIM technology, can design different decoration model, through the BIM software rendering and widely, and other functions, can be the designer's creative inspiration and image vividly presented, provide users with visual decorate model, including lighting, sanitary ware, furniture, materials and equipment, such as Fig. 3. Through design changes can decorate module, flexible change module design such as color, style, combination, at the same time also can consider to design a variety of different solutions for the user to choose, to communicate the problems solved in time, the scheme of data and material list completes the interaction, easy to use in the construction [6].

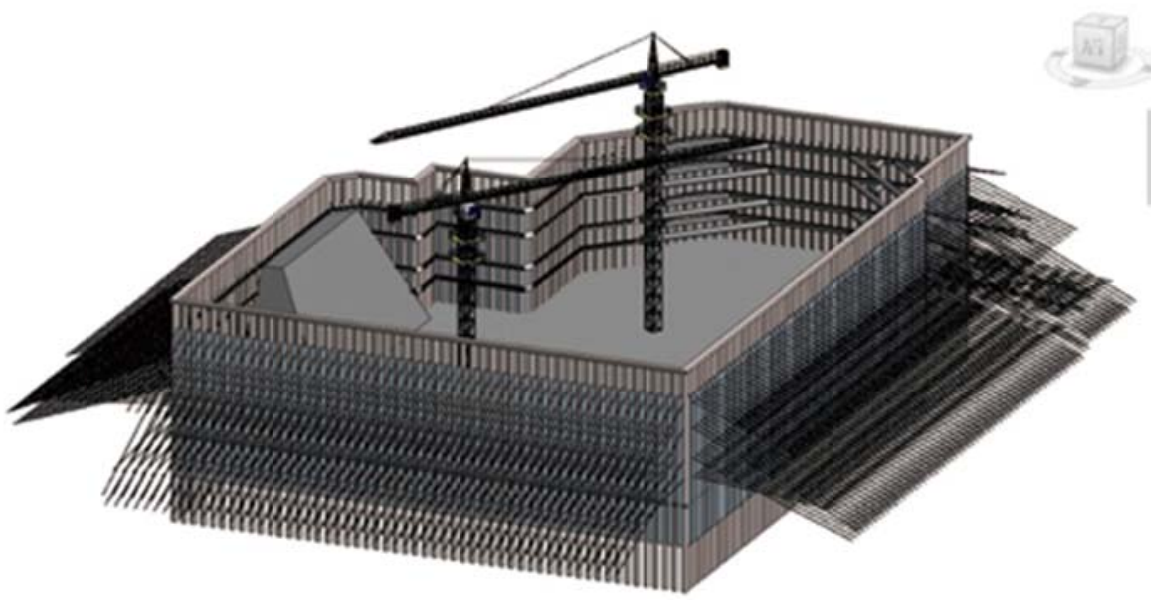

Fig. 3 The design of the visual model

BIM auxiliary residential energy-saving design.BIM the simulation and analysis on the performance of ability, is the comprehensive data and information integration, through scientific 
means to show the image display, is the understanding of the building performance, get the effect of building performance is the most realistic [6].Energy-saving design of the building has a relatively important position, its main purpose is to reduce building energy consumption, the appearance of the building, the location and external structures for a role with the external environment.Different building design will have different effect on energy consumption, building energy performance of building design has a leading role.

\section{Conclusion}

BIM technology has been over ten years of development, more and more people have noticed that the solution to China's current problems existing in the construction industry and China's construction industry core competitiveness has a very realistic and urgent meaning. BIM for building the application of analysis, focusing on BIM moves of residential design are discussed, based on BIM technology characteristics, determines its application in architectural design categories, including space planning, building production, analysis of energy saving, and the management of the late. BIM technology effectively promoted the development of the computer aided architectural design, not only save the design time of architectural design personnel, improve the overall quality of the architectural design, and to promote the development of construction industry, create more social benefits and economic benefits. But BIM applicable fields have not been fully developed, hope to get great progress on the development of the future.

\section{References}

[1] Y.Z. Nie, BIM technology in the application of the civil building design study, Construction of Tianjin science and technology, 2012, vol. (1),pp. 74-76.

[2] W.W. Zhou, BIM technology application in the architectural design, Modern decoration and practices, 2013,vol. (3), pp. 17-22.

[3] Y.F. Long and D. Hong,Application of BIM technology in the construction of industrialization, 2012, vol. (9), pp. 79-82.

[4] F. Y. Long, BIM technology applied in the structural design of discussion and case, Journal of information technology in civil engineering and construction, 2010, vol. (11), pp. 23-27.

[5] D.G. Guo, BIM architectural design and construction management research based computer aided, JournalXiamen University, 2014, vol. (4), pp. 18-21.

[6] T. H. Zeng, Development and application of building energy efficiency design software based on BIM technology, Journal of Tsinghua University, 2012, vol. (3), pp. 12-15. 